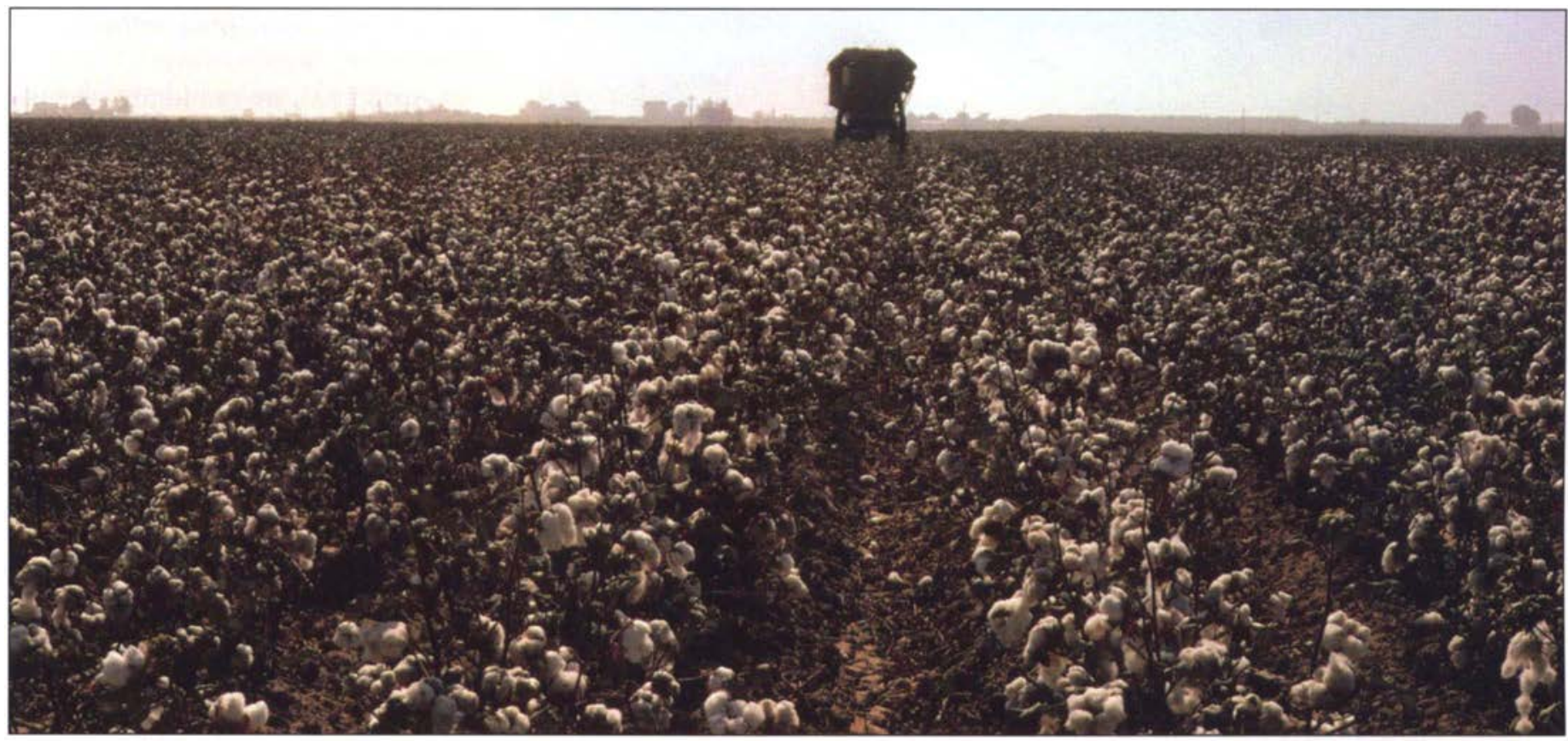

Because of the lack of consistently effective organically acceptable products, organic plants are frequently not completely desiccated at harvest. Green leaves can stain cotton fibers. Researchers and growers are optimizing organically acceptable defoliation strategies.

\title{
Preliminary studies show yield and quality potential of organic cotton
}

Sean L. Swezey a Polly Goldman a Ralph Jergens a Ron Vargas

For three years (1993 to 1995), we monitored organically and conventionally managed cotton fields in Madera County, and measured pest and beneficial arthropod populations, plant growth and development parameters, nutrient status, plant density, yields and lint quality. Square (flower bud) retention was similar in the two systems, although western tarnished plant bugs (Lygus hesperus or lygus bugs) were significantly more abundant on several dates in the organic fields. On most dates, populations of the predatory insects Geocoris spp. were significantly higher in the organic than in the conventional fields. Lint yields were not significantly different for the two production systems in any of the three years, but were lower than county averages in all years. In 1994, lint quality in the two treatments differed in that color grades were more variable in the organic cotton bales. Late spring rains also affected planting success in each year and the shortened seasons in 1994 and 1995 generally kept yields in both treatments at or below two bales per acre.
California's cotton production ranks second only to Texas, with over 1 million acres of irrigated cotton between 1993 and 1997. This comprises about $15 \%$ of total U.S. cotton production and about $4 \%$ of the global total. Cotton is the fifth largest contributor to total farm income in the state, and regularly has a gross value of approximately $\$ 1$ billion in seed and lint (CDFA 1995).

Cotton is one of the largest users of agricultural chemicals of any commodity produced in the state. In each production year since 1970 (the first year of statewide pesticide use reporting), cotton farmers have ranked among the three highest total users of 


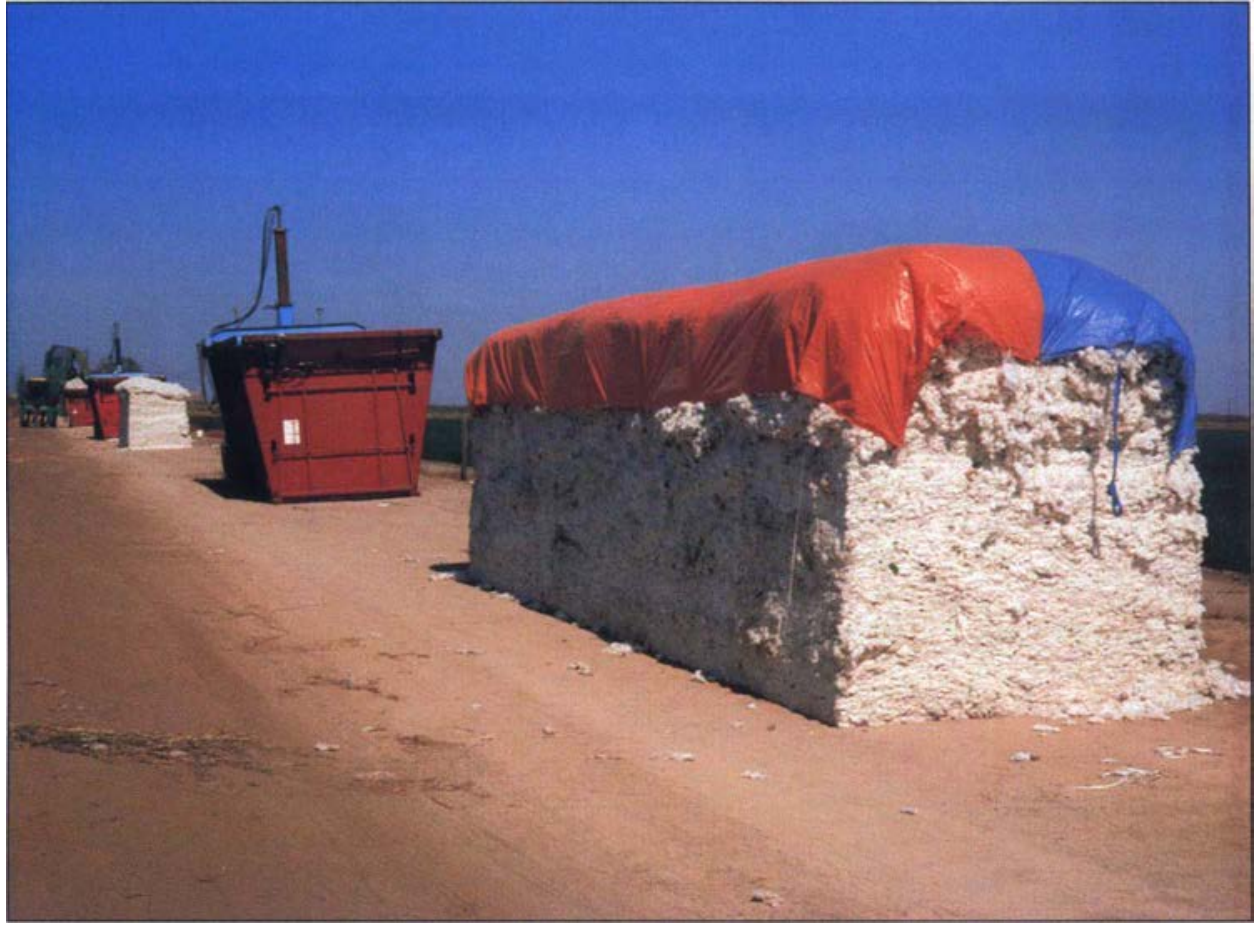

Following harvest, organic and conventional cotton are compressed into separate modules for transfer to the gin. Special handling is necessary to ensure segregation of organic and conventional cotton at the gin.

pesticide active ingredients (including those in insecticides, nematicides, fungicides, herbicides, desiccants and defoliants) among all crops (CDPR 1992; CDPR 1994). Many insecticides and miticides are becoming less effective as arthropods build resistance to these chemicals (DANR 1998; GraftonCardwell et al. 1997). Along with decreased effectiveness, the rising cost of inputs and impact of environmental regulations have stimulated interest in cotton production systems which reduce or do not require conventional synthetic chemicals.

Organic production methods replace synthetic chemicals with physical or biologically based management techniques including compost applications, biological control agents and modified tillage techniques. While addressing the major concerns regarding potential environmental impacts of conventional agriculture, organic production introduces several potential problems, such as: increased arthropod damage; weed competition, particularly from perennial weeds; nutrient deficiencies; decreased product quality, due to the unavailability of effective harvest aids; increased cost of management practices; and market uncertainties such as fluctuating price premiums for organic products.

In a 3-year comparison between commercial organic and conventional cotton production systems, we used a conversion study protocol established in previous studies of apples (Swezey et al. 1994) and strawberries (Gliessman et al. 1996). Insect populations, plant development and nutrient status were monitored throughout the growing season, and yields and lint quality were determined at the end of the season. Economic and energetic analyses of the two production systems will be presented elsewhere. Our conversion study research highlights the factors that constrain reduction of agrochemical use in cotton. The results provide direction for future study of individual factors that affect organic cotton farming systems.

\section{Plot selection and management}

In California, organic production practices are usually verified by thirdparty certifying organizations, under provisions of the California Organic Foods Act of 1990 . For certification under state law, fields must have at least ment. Fields under organic managea 3-year history of organic manage- ment are referred to herein as organic, although some were not certified until the end of the 3-year study.

In April 1993, we randomly selected four organic cotton fields within a 1-mile radius of Road 7 and Avenue 24, 8 miles east of Chowchilla, in Madera County. We matched these organic fields with four conventional fields planted to the same variety ('San Joaquin Acala-Maxxa'), within the same initial 2-week period each year (mid-April to early May), and located within the same 1-mile radius as the organic fields. Individual production practices and inputs for all fields were determined by the growers.

The specific fields sampled differed during the study due to crop rotations. Replicate fields ranged from 20 to 70 acres. Area soils are mainly Grangeville sandy loam and Chino sandy loam with streaks of Tujunga loamy sand. The soils are quite heterogeneous, and can have problems with drainage, salinity, sodicity (sodium content) or low nutrient content, requiring intensive management for crop production. Soils were tested prior to planting and after harvest, and ranged from 6.9 to 8.1 in $\mathrm{pH} ; 5.1$ to $13.7 \mathrm{meq} / 100 \mathrm{~g}$ in CEC (milliequivalents per 100 grams in cation exchange capacity); 11 to 104 parts per million (ppm) (nitrate-nitrogen); 11 to 47 ppm phosphorus; and 62 to 400 ppm potassium. There were no significant differences in these measures between the organic and conventional treatments.

All of the organic fields were managed by a single grower throughout the study, whereas the conventional fields were managed by three different growers in each of the 3 years. This difference was necessary because only one organic cotton grower farmed in the region at the onset of the project. We used several conventional growers rather than a single one to study the range of conventional production practices and yields in the region. Although this difference between treatments introduces more variation in the conventional treatment, we felt it was necessary to avoid simply comparing two different cotton growers. 
Organic and conventional fields were planted in mid-April in 1993 and 1994, and in early May in 1995 (late rains delayed planting). In 1994, all the organic fields were replanted in late April to mid-May due to poor emergence associated with heavy late-spring rains. There were consistent differences between the planting densities of conventional and organic cotton; conventional planting densities were usually between 35,000 and 55,000 plants per acre (standard densities in this system) and organic densities were usually 20,000 to 35,000 plants per acre. These density differences were growerdriven; the organic grower believed that lower plant densities help prevent disease and pest outbreaks.

The organic fields were fertilized with a late-winter application of 6 tons per acre composted chicken manure, whereas the conventional fields received synthetic nitrogen fertilizer at planting and during the growing season. In addition, up to two applications of foliar nutrients were applied in the organic fields as an in-season nitrogen source. Organic fields also received year-end zinc sulfate applications as a nutritional supplement and potential harvest aid. The conventional fields received preemergence herbicide applications at planting, and one to three in-season miticide and/or insecticide sprays. The rates and timing of chemical applications were decided by individual growers and their pest control advisors, based on field sampling.

Conventional fields also received one growth-regulator (mepiquat chloride/Pix) application and two end-ofseason defoliant applications. In 1994, organic fields were topped in midAugust with a mechanical tobacco topper to control end-of-season rank growth and to aid boll maturation. Plants were not topped in the other two years. All of the fields were cultivated with similar tillage implements and hand-weeding for in-season weed control; cultural weed control was performed more frequently in organic fields than in conventional fields.

Furrow irrigation schedules were similar between management types.
However, the organic grower employed alternaterow watering in early-season irrigation to help control pest populations and conserve water. Organic fields also received periodic spring releases of insectary-reared green lacewing (Chrysoperla carnea) larvae, at an average total seasonal rate of 5,000 larvae per acre, for management of key arthropod pests (spider mites, western tarnished plant bugs and aphids). Organic fields were picked following varying levels of leaf desiccation resulting from the preharvest application of zinc sulfate.

\section{Plant growth and yields monitored}

We determined average lint yields in each treatment in all three years using gin records obtained from growers. In 1995, records from one conventional field were not available; instead, yield was estimated from hand-harvested samples taken just prior to harvest. One 1/1,000th-acre linear row sample was hand-harvested from a random location within each quarter of the field. We estimated yields using a formula that corrected for harvest efficiency and lint turnout. These yield estimates were made in 1994 and 1995 for all of the fields. The values obtained were on average $6 \%$ lower than gin-record yields with a maximum error of $20 \%$.

In 1994, we did a complete analysis of cotton lint quality, also using gin records. Lint quality, an important determinant of lint price, is measured by a number of parameters. The most important are fiber length, fiber strength, fiber micronaire (diameter), color grade (a measure of lint staining caused by foreign material in the harvest) and leaf content.

At regular intervals during the growing season (biweekly in 1993, weekly in 1994 and 1995), 20 randomly selected cotton plants were removed from each of the replicate fields. We mapped the architecture of these plants using guidelines of the UC CALEX/Cotton expert system computer software (DANR 1991) and Cotton Plant Mapper (CPM) software. We measured plant height; height-to-node ratio (HNR); number of nodes; number of vegetative and fruiting branches; retention of squares, flowers and bolls in the bottom five and top five first-fruiting positions; and retention of total first-position bolls per plant. On the final sample date each season, complete maps were made showing the positions of all bolls on each plant.

We determined plant nutrient status by pooling 20 (in 1993) or at least 50 (in 1994 and 1995) mainstem leaf petioles per treatment replicate, at each of four cotton development stages during each season: first square (late June to early July); first bloom 


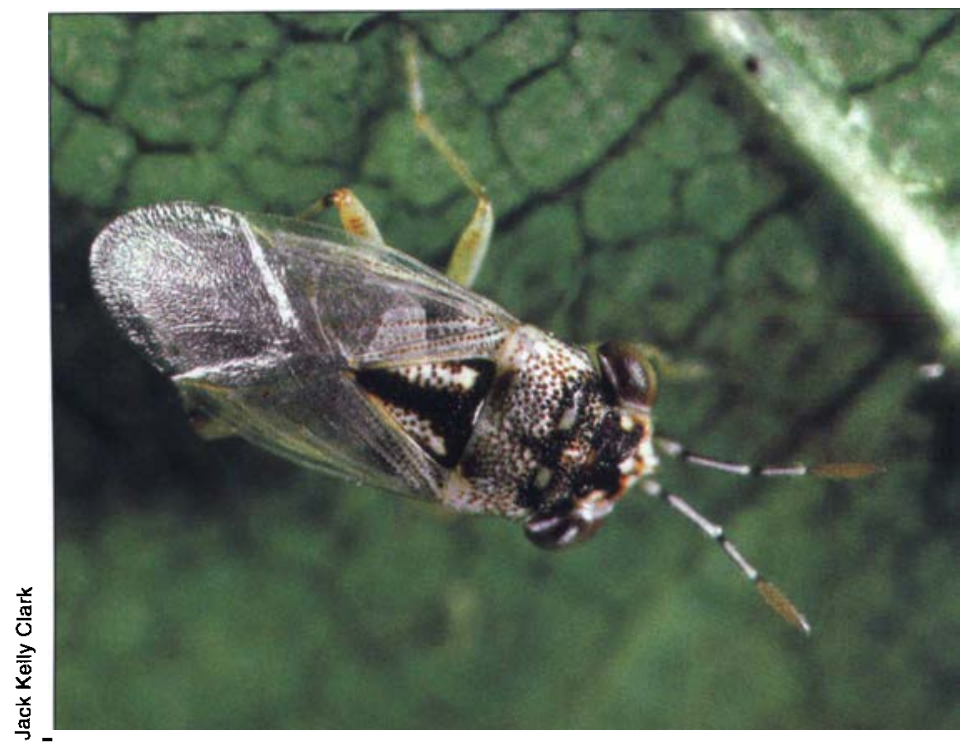

Generalist predators, such as bigeyed bugs, were more abundant in organic than conventional fields in all 3 years of the study. These beneficial insects feed on lygus bug eggs and nymphs and all stages of spider mites and other plantfeeding insects. (late July); peak bloom (midAugust); and first open-boll (early September) stages. These samples were analyzed for major and minor nutrients at a certified laboratory. $\mathrm{Nu}$ trient analysis consisted of nitrogen (total and nitratenitrogen), sulfur, phosphorus, potassium, magnesium, calcium, iron, boron, copper, manganese, zinc and sodium.

\section{Pests, natural enemies monitored}

To sample arthropods, we used sweep nets and visual leaf counts.

TABLE 1. Year-end summary of cotton statistics, 1993-1995

\begin{tabular}{|c|c|c|c|}
\hline Measurement & Year & Organic & Conventional \\
\hline \multirow[t]{3}{*}{ Plant height } & 1993 & $42.0 \pm 1.19^{*}$ & $41.2 \pm 2.29$ \\
\hline & 1994 & $35.0 \pm 0.76 t$ & $32.6 \pm 1.23$ \\
\hline & 1995 & $33.3 \pm 2.50$ & $32.0 \pm 2.11$ \\
\hline \multirow{3}{*}{ No. of nodes } & 1993 & $21.3 \pm 0.53$ & $19.28 \pm 0.90$ \\
\hline & 1994 & $17.0 \pm 0.38$ & $17.04 \pm 0.45$ \\
\hline & 1995 & $18.6 \pm 1.12$ & $17.5 \pm 0.97$ \\
\hline \multirow[t]{3}{*}{ Height-to-node ratio (HNR) } & 1993 & $2.0 \pm 0.05$ & $2.2 \pm 0.11$ \\
\hline & 1994 & $2.1 \pm 0.04$ & $1.9 \pm 0.08$ \\
\hline & 1995 & $1.8 \pm 0.10$ & $1.8 \pm 0.12$ \\
\hline \multirow[t]{3}{*}{ No. of vegetative nodes } & 1993 & $6.1 \pm 0.35$ & $6.1 \pm 0.25$ \\
\hline & 1994 & $6.0 \pm 0.31$ & $5.5 \pm 0.47$ \\
\hline & 1995 & $5.0 \pm 0.21 \ddagger$ & $5.8 \pm 0.25$ \\
\hline \multirow[t]{3}{*}{ No. of fruiting branches } & 1993 & $17.0 \pm 0.45 \ddagger$ & $14.2 \pm 0.89$ \\
\hline & 1994 & $11.0 \pm 0.41$ & $11.7 \pm 0.20$ \\
\hline & 1995 & $13.7 \pm 1.23$ & $11.7 \pm 1.10$ \\
\hline \multirow[t]{3}{*}{ No. of 1 st position open bolls } & 1993 & $8.5 \pm 0.41 \ddagger$ & $5.9 \pm 0.60$ \\
\hline & 1994 & $5.1 \pm 0.43$ & $5.9 \pm 0.25$ \\
\hline & 1995 & $5.5 \pm 0.61$ & $4.3 \pm 0.36$ \\
\hline \multirow[t]{3}{*}{ No. of 2 nd position open bolls } & 1993 & $5.0 \pm 0.20 \ddagger$ & $2.0 \pm 0.40$ \\
\hline & 1994 & $3.4 \pm 0.23$ & $2.4 \pm 0.51$ \\
\hline & 1995 & $2.5 \pm 0.60$ & $1.7 \pm 0.46$ \\
\hline \multirow[t]{3}{*}{ No. of 3rd position + open bolls } & 1993 & $1.9 \pm 0.33 \ddagger$ & $0.5 \pm 0.18$ \\
\hline & 1994 & $4.3 \pm 0.89 \ddagger$ & $1.0 \pm 0.50$ \\
\hline & 1995 & $1.7 \pm 0.68$ & $0.5 \pm 0.06$ \\
\hline \multirow[t]{3}{*}{ B-5 retention§ (\%) } & 1993 & $76.0 \pm 0.05 \ddagger$ & $48.0 \pm 0.05$ \\
\hline & 1994 & $52.0 \pm 0.10$ & $56.0 \pm 0.07$ \\
\hline & 1995 & $66.0 \pm 0.01 \ddagger$ & $54.0 \pm 0.05$ \\
\hline \multirow[t]{3}{*}{ Plant density } & 1993 & $29625.0 \pm 625 \ddagger$ & $49813.0 \pm 2511$ \\
\hline & 1994 & $23688.0 \pm 640 \ddagger$ & $35750.0 \pm 2704$ \\
\hline & 1995 & $29750.0 \pm 4438$ & $38875.0 \pm 3993$ \\
\hline \multirow[t]{3}{*}{ Yieldף (bales/acre) } & 1993 & $2.0 \pm 0.11$ & $1.8 \pm 0.13$ \\
\hline & 1994 & $1.5 \pm 0.13$ & $2.0 \pm 0.19$ \\
\hline & 1995 & $1.3 \pm 0.24$ & $1.4 \pm 0.07$ \\
\hline \multicolumn{4}{|c|}{$\begin{array}{l}\text { "Values shown are averages } \pm 1 \text { S.E.M. } \\
\text { †The } 1994 \text { organic plant heights reflect August topping. } \\
\text { †Significant difference from same year conventional measurement, } P<0.05 \text { (one-way ANOVA) } \\
\text { §B- } 5 \text { retention }=\% \text { of retained } 1 \text { st position open bolls on the bottom } 5 \text { fruiting branches. } \\
\text { ๆYields are from gin records (see text for exception). }\end{array}$} \\
\hline
\end{tabular}

Sampling was conducted biweekly in 1993 and weekly in 1994 and 1995. Western tarnished plant bugs, better known as lygus bugs, and generalist predators (mainly Orius tristicolor, Geocoris spp., Nabis sp., Zelus sp. and Chrysoperla spp.) were sampled with four 50-sweep samples per field.

Thrips, spider mites and aphids, as well as identifiable eggs of the previously mentioned predator species, were sampled by examining the eighth mainstem leaf from the plant apex of each of the 20 plants mapped per field. We measured thrips and spider mite abundance using presence/absence counts on each leaf. Because aphids were so abundant in 1995, we used a per-leaf ranking system $(1=$ no aphids; $2=1$ to 10 aphids; $3=11$ to 100 aphids; 4 = greater than 100 aphids) rather than an absolute count. There were negligible numbers of lepidopteran pests.

Neither weed abundance nor plant pathogens were assessed. We did not notice any major differences in these potentially yield-affecting factors between organic and conventional fields throughout this study.

All data were analyzed by one-way, single-factor analysis of variance ( $F$ ratio) tests, transforming data if necessary to equalize variances. Rank tests (Kruskal-Wallis) were used to analyze data which were not normal following transformations. Plant density was included as a covariant in yield analyses. Yields over the whole study were also compared using two-way ANOVA, with year as a block.

\section{Treatment performance compared}

Cotton lint yield and quality. Cotton lint yields did not differ significantly between the two production systems in any year, although in 1994 differences were near significance $(\mathrm{P}=$ 0.07) (table 1). Yields were lower than average yields of Madera County, but paralleled the pattern of county yield declines during the 3-year period (countywide averages in bales per acre were $2.7,1993 ; 2.6,1994 ; 2.0,1995)$. The variable soils of the study area could account for some of the difference between study yields and county average yields. 
The 1994 analysis of lint quality showed that color grades were more variable in the organic fields. Cotton lint is graded using a colorimeter, which measures grayness, yellowness and spotting, all of which can affect price. The three best grades, in descending order, are 11 ("good middling"), 21 ("strict middling") and 31 ("middling"). Eighty-eight percent of the bales from conventional fields were classified as either 21 or 31 , compared to only $50 \%$ of the organic bales (there were no grade 11 bales in either system). The majority of the remaining organic bales were classified as light-
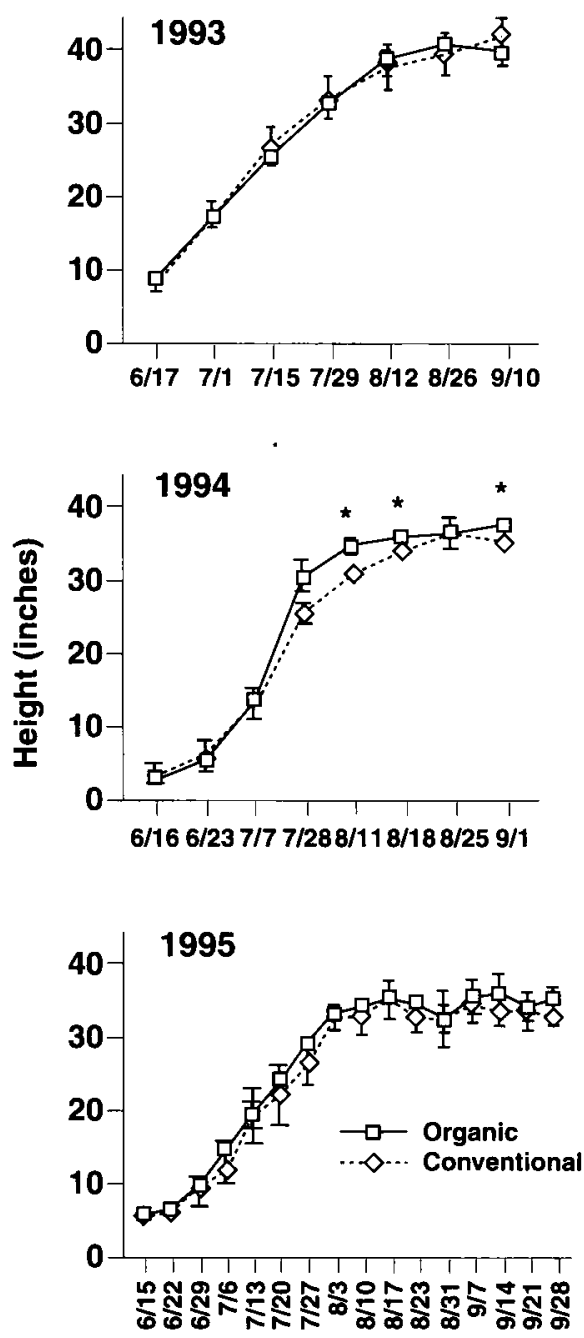

Fig. 1. Plant height $(x \pm$ S.E.M.) in 1993, 1994 and 1995. *Indicates significant difference (Kruskal-Wallis, $P<0.05$ ) between treatments on that sample date. spotted grades, which can carry a lower premium on the conventional market. There were no significant differences in leaf content, staple length, strength or micronaire between the two treatments.

Plant development and nutrient analysis. Most plant growth parameters measured during the production seasons did not differ between the organic and conventional treatments.

One exception was 1994 plant heights, which were significantly greater in organic for three late-season dates (fig. 1). In August 1994, a tobacco topper was used on the organic plants in an
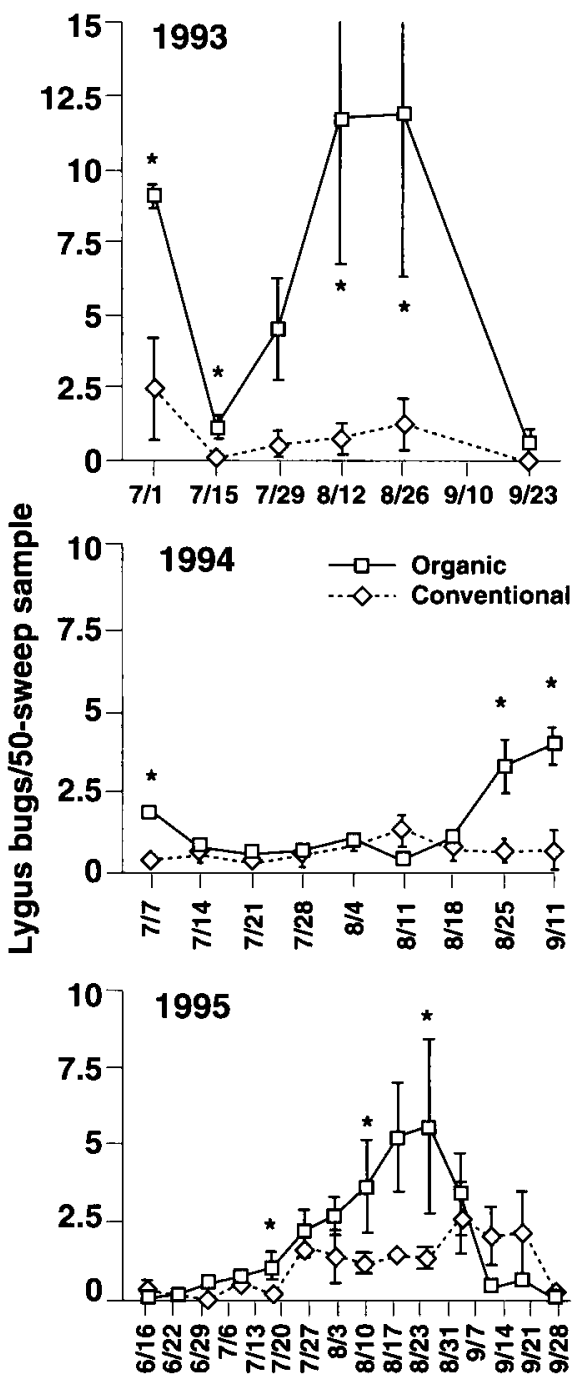

Fig. 2. Western tarnished plant bug (Lygus hesperus) abundance ( $\times \pm$ S.E.M.) in 1993, 1994 and 1995. *Indicates significant difference (Kruskal-Wallis, $P<0.05$ ) between treatments on that sample date. attempt to regulate this late-season rank growth and redirect plant energy to boll maturation.

Similarities between the two treatments were also evident at harvest. Plant height, number of nodes and HNR were the same in the two treatments (table 1). The number of vegetative nodes, fruiting branches and firstposition (adjacent to the mainstem) open bolls each differed in only 1 year (1995 for vegetative nodes, 1993 for fruiting branches and first-position open bolls). In contrast, the organic plants had consistently more outerposition (further from the mainstem)
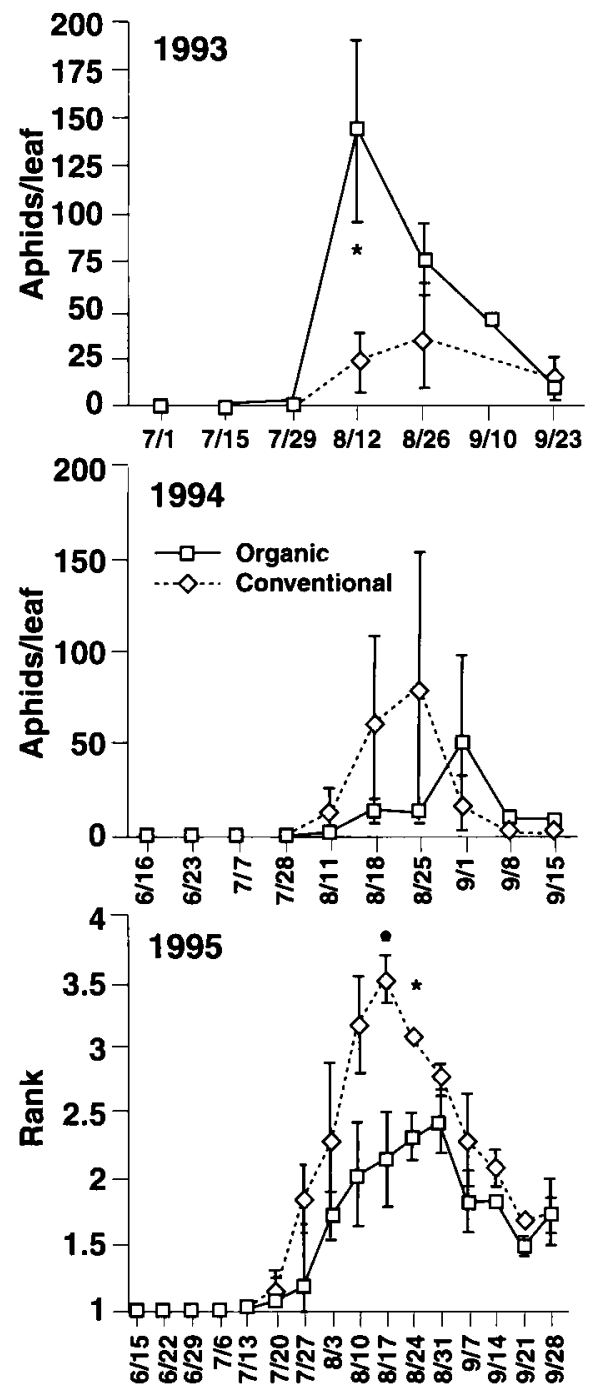

Fig. 3. Aphid abundance ( $x \pm$ S.E.M.) in 1993 1994 and 1995. *Indicates significant difference (Kruskal-Wallis, $P<0.05$ ) between treatments on that sample date. In 1995, aphid abundance is presented as a rank: $1=$ no aphids, $2=1$ to 10 aphids, $3=11$ to 100 aphids, 4 = greater than 100 aphids. 
open bolls, an architecture related to the lower plant density. Additionally, more bolls were produced early in the season (bottom five first-position bolls) in the organic fields in 1993 and 1995.

Based on sufficiency guidelines developed for the nutrients of cotton (DANR 1996b), nutrient levels in both production systems were within the adequate range for most of the sampling dates.

Arthropod pests and natural enemies. Lygus bugs were significantly more abundant in the organic than in the conventional fields on several sampling dates (fig. 2). In 1993, differences

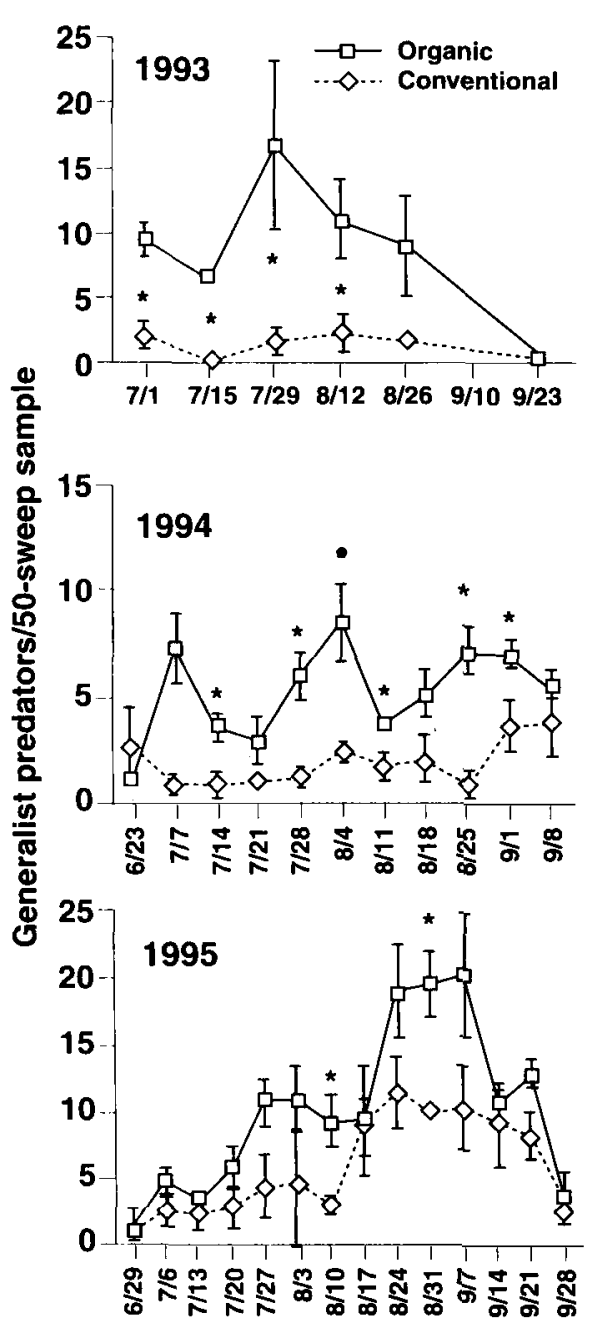

Fig. 4. Total generalist predator abundance $(\times \pm$ S.E.M.) in 1993, 1994 and 1995. *Indicates significant difference (ANOVA, $P<0.05$ ) between treatments on that sample date. were pronounced on most sample dates. In 1994, differences were significant on the first sampling date and last two dates only; all three of these dates were during periods in which the presence of lygus bug causes little harm to cotton. The trend in 1995 was similar to that in 1993: lygus bugs were more abundant in the organic system on most of the August sampling dates. In the majority of cases, differences were due to adult lygus bugs; nymphal numbers were similar in organic and conventional fields.

Thrips and mite abundance were not statistically different between the organic and conventional treatments

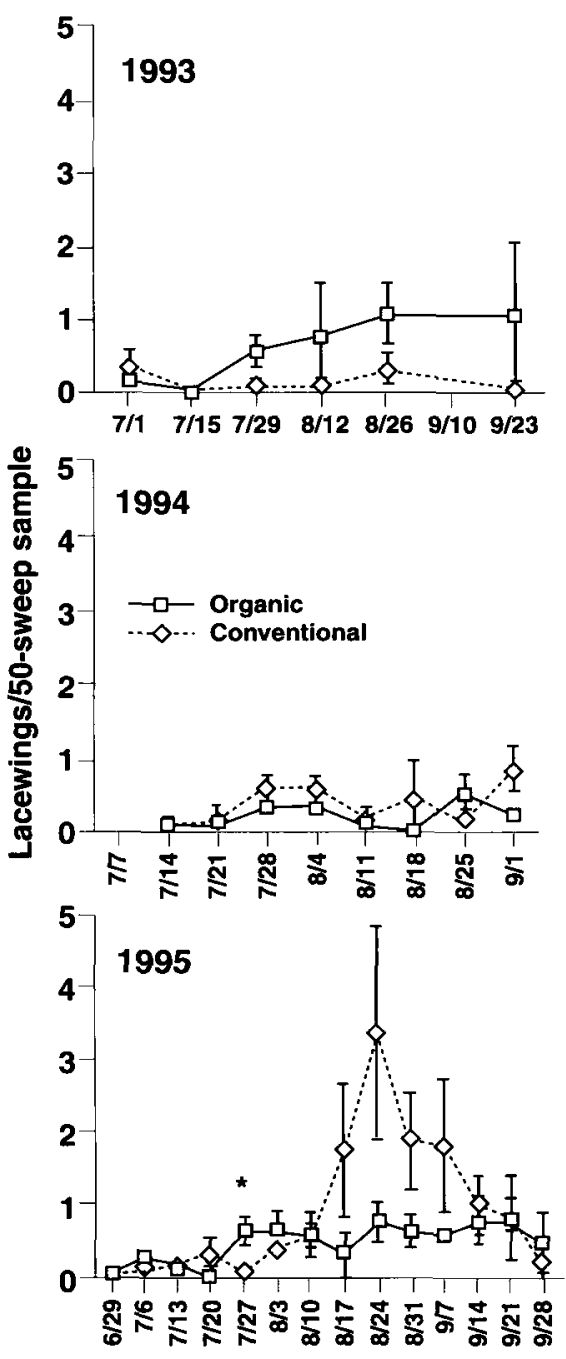

Fig. 5. Green lacewing abundance $(x \pm$ S.E.M.) in 1993, 1994 and 1995. *Indicates significant difference (Kruskal-Wallis, $P<$ 0.05 ) between treatments on that sample date. in any of the three years (fig. 3). In 1993 there were significantly more aphids in the organic plots at midseason. These trends reversed in 1994 and 1995, when midseason aphid abundance was higher in conventional fields; of these two years, the difference was only significant in 1995, when aphid numbers markedly increased in conventional fields.

Total generalist predators were consistently more abundant in the organic fields (fig. 4). Half of the predator complex was composed of Geocoris spp. (bigeyed bug, mostly G. pallens and $G$, atricolor, with some $G$.

punctipes), so Geocoris spp. abundance drove most of the predator trends. However, abundance of many other predators followed the same pattern. The rest of the complex consisted of Orius tristicolor (minute pirate bug), Nabis sp. (damsel bug), Chrysoperla spp. (green lacewing), Zelus sp. (assassin bug), coccinellids (ladybird beetle) and spiders. Despite releases of $C$. carnea throughout the production season in the organic system, population densities of Chrysoperla spp. were only greater in organic fields in one year, 1993, a year of high populations of aphids in the organic fields (fig. 5). In 1995, lacewings were more abundant in conventional fields during many dates of aphid infestation.

\section{Similar yields and quality}

Yields in both production systems decreased in the third year of this study, and decreased in the organic system over all 3 years. This trend mir. rored countywide average cotton yields during the same 3 years. Yield losses were due mainly to early-seasor rains in 1994 and an extremely cool, wet early 1995 season, which delayed planting dates. In 1994, the organic fields had poor emergence and were replanted, one a total of three times. In all 3 years, yields did not differ significantly between the two treatments, although there was a numeric trend of relatively greater yields in conventional fields. This may be important because in our more recent studies, us ing more growers and more fields, organic yields in some years have been 
significantly lower than conventional yields. The organic fields were planted at lower densities; thus, organic plants outyielded conventional plants on a per plant basis. Organic plants also relied on outer-position bolls for about half of the yield; by contrast, in the conventional treatment about onethird of the yield was derived from outer-position bolls.

This difference in per-plant performance was most likely linked to the lower plant densities in the organic system: prior research suggests that relative importance of first-position bolls decreases as plant density decreases (Kerby et al. 1987). It is not known if higher planting densities in organic fields would increase per-acre yields.

Additionally, reliance on high perplant lint production (from outerposition bolls) brings up important concerns. First, since cotton grows in an indeterminate fashion, outer-position bolls mature later than first-position bolls. Thus, low-density plantings have a longer window of time during which potential damage can occur (for example, damage to squares and bolls by weather or pests). Second, outerposition bolls may yield lower-quality lint due to a shortened development time prior to harvest (Hsieh et al. 1995) and/or higher incidence of nondying fibers.

In 1994, color grades were slightly lower for the lint from organic fields. This quality difference was small enough that organic bales were not discounted. In conventional cotton production systems, chemical defoliants promote leaf drop, thus preventing lint staining in the bales of harvested cotton. Staining can decrease lint value, as it requires processors to perform extra steps prior to dying the fiber.

There is currently no equally effective, organically acceptable method of leaf desiccation and removal, thus organic bales tend to have more leaf trash and stained lint. Staining may also indicate that the lint was wet; high moisture (above 12\%) can reduce lint quality due to bacterial decomposition and heating in storage. The other important measures of cotton quality - fiber length, fiber strength, micronaire and leaf content - did not differ significantly between the two treatments. Length, strength and micronaire are more indicative of the intrinsic properties of cotton than color grades. These results indicate that neither

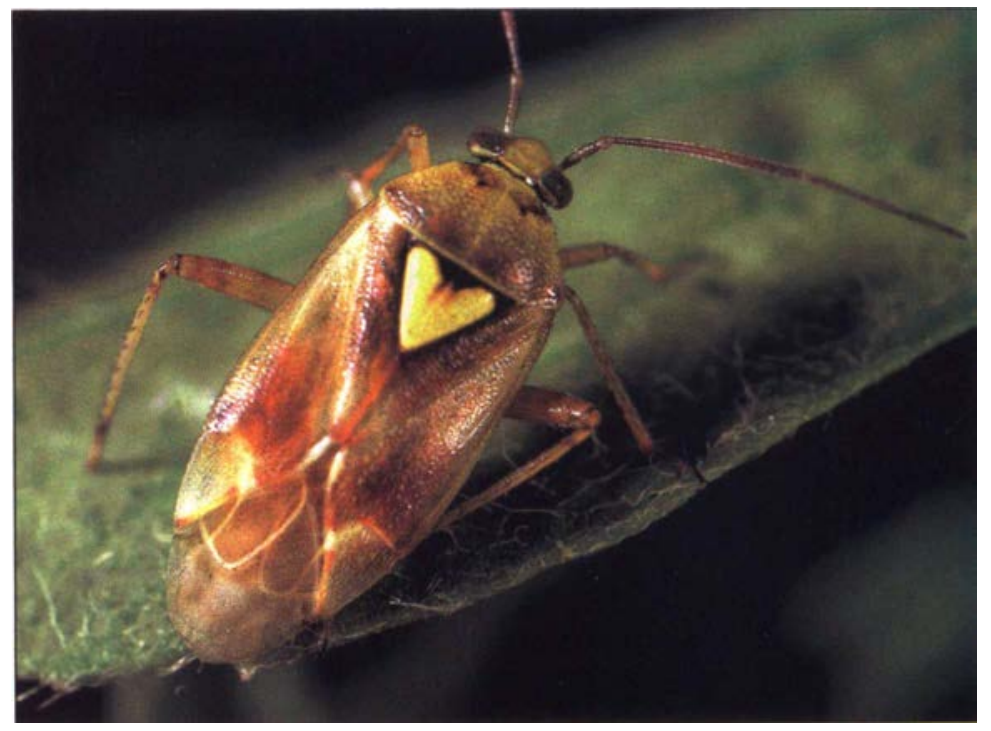
in-season organic production methods nor boll position on the cotton plant affected overall 1994 fiber quality as measured at the gin.

Plant development and nutrient analysis. Similar values for in-season plant development measures were obtained for plants under the conventional and organic treatments. These similarities did not, however, reflect important differences in boll production strategies between the two systems. In conventional systems, the emphasis is on production of first-position bolls. Plants in organic fields produced more outer-position bolls than did conventional plants. Production from these outer positions was crucial in obtaining organic yields similar to the conventional yields in the study. Thus, to more accurately assess production progress in organic fields, growers may need modified in-season and final plant mapping programs that not only reflect this unique plant canopy development, but also consider growth patterns in the absence of chemical growth regulators and defoliants, and pest dynamics particular to unsprayed fields.

Overall similarities between nutrient levels in organic and conventional plants demonstrate that organic fertilization methods provided adequate nutrient levels. Soil processes are frequently quite slow, however; it remains to be seen what long-term effects organic management may have
The western tarnished plant bug (WTPB), also called lygus bug, is a major cotton pest in the northern San Joaquin Valley. Although WTPB adults were often more abundant in organic than conventional fields, there was no evidence that they caused greater damage in the organic fields.

on soil and subsequent plant-nutrient

\section{Arthropod pests and natural} enemies. Lygus bugs feed on cotton squares (flower buds) and cause flower abortion, which may result in fewer bolls and lower yields. (DANR 1984, 1996a). Interestingly, although lygus bug numbers were frequently higher in the organic system, this was not reflected in boll retention (table 1 ), suggesting that lygus bugs did not cause increased damage in the organic fields. The reasons for this are not clear, but may be related to regional cropping patterns such as the large acreage of alfalfa, a preferred host of lygus bug (Sevacharian and Stern 1974), planted in the area. Adult lygus bugs in the cotton fields may have immigrated from alfalfa fields in which they were feeding and subsequently may not have fed extensively on cotton. If this were the case, only lygus bug nymphs, which were present at much lower densities than adults, would be problematic in cotton fields. Results from the current study are encouraging for local cotton growers in general, and for organic growers in particular, since insecticide sprays did composition. 
not appear to be necessary for preventing excessive lygus bug damage in this area during our study.

Aphids (mostly Aphis gossypii) are also a major pest in San Joaquin Valley cotton, reducing plant vigor when present in midseason and causing sticky cotton from their honeydew when present at boll opening. Peak aphid abundance occurred in midseason in all three years. Sticky cotton, which is mainly a concern at harvest and during ginning, was not reported in either production system for any of the years of our study. This suggests that aphid populations could be successfully managed through conservation of natural enemies.

Conventional cotton farmers apply chemical insecticides and miticides to control arthropod pests. However, although chemical pesticides were not used, arthropod pest problems did not occur in the organic plots. Predatory insects, which overall were more abundant in organic fields, may have kept arthropod populations under control. Green lacewings released in the organic fields may have contributed to arthropod pest control; however, lacewings were not significantly more abundant in the organic fields. It is possible that aphid numbers in the organic fields were too low to encourage lacewings to remain.

\section{Organic vs. conventional cotton}

Conversion of cotton production in the northern San Joaquin Valley to organic management did not result in statistically significant overall yield differences when compared with conventional cotton production, although yields in both systems averaged $30 \%$ lower than county averages during the 3-year study. Yields in relation to county averages have since improved, according to subsequent research involving more fields and growers by the UC collaborative project Biological Agriculture Systems in Cotton (BASIC). In 1996, yields in BASIC organic fields averaged 2.2 bales per acre, compared with 2.7 in BASIC conventional fields. The 1996 Madera County average yield was 2.7 bales per acre.
Organic plants in our study grew as vigorously as conventional ones, and were not impacted by any pests in a statistically different manner. Organic fields maintained large populations of natural enemies, often higher than those in conventional fields. Fiber quality, in terms of fiber length, strength and micronaire, was not compromised by the strategies used in the organic production system (although fiber quality is a potential issue with the organic production methods described in this paper because of increased reliance on outerposition bolls).

Per-bale operational costs of production in this organic system can be higher than those of the conventional system, mainly because of labor costs of hand-weeding. Materials costs (insecticides, defoliants, fertilizers) are consistently lower in organic cotton fields. Growers have relied on organic price premiums to offset increased weed control and other costs, but lack of stability in both supply and demand has led to similarly fluctuating premiums. Further research on alternative weed control approaches could improve economic competitiveness of organic cotton.

A major production parameter that still differs between the two systems is crop preparation. Lack of complete desiccation and leaf drop in organic fields can result in more bales with stained lint, higher leaf content in the seed cotton, and the necessity of multiple harvest runs. New approaches to organic crop preparation methods, including the use of nonsynthetic defoliants, and water, nutrient and physical manipulations, will be necessary for cleaner harvest in organic cotton production systems.

\section{S.L. Swezey is Specialist and P.}

Goldman is Post-Graduate Researcher,

Center for Agroecology and Sustainable

Food Systems, UC Santa Cruz; R. Jergens is Agronomist and Nutritional Consultant, New Era Farm Service, Tulare; and R. Vargas is County Director and Farm Advisor, UCCE Madera County.
The authors thank Claude and Linda Sheppard, Sean Moss and the other cotton growers who allowed access to their fields. They also thank Matt Grieshop, Kevin Dunn, Katie Siegler and Louis Wilscher for their assistance in fieldwork, and two anonymous reviewers for their detailed and extremely helpful comments. This research was funded by the Clarence E. Heller Charitable Foundation, the Organic Farming Research Foundation, and the California Energy Commission. The authors thank Bruce Hirsch, Bob Scowcroft and Ricardo Amon, who provided a supportive, personal link with these funding agencies.

\section{References}

California Department of Food and Agriculture (CDFA). 1995. California Agricultural Resource Directory. 1994. Sacramento. $96 \mathrm{p}$. California Department of Pesticide Regulation (CDPR). 1992. Pesticide Use Report, 1991. Sacramento. 297 p.

California Department of Pesticide Regulation (CDPR). 1994. Pesticide Use Report, 1993. Sacramento. $306 \mathrm{p}$.

Division of Agriculture and Natural Resources (DANR), UC. 1984, 1996a. Integrated Pest Management for Cotton in the Western Region of the United States. 2nd edition, UC DANR Publication 3305. 164 p.

Division of Agriculture and Natural Resources (DANR), UC. 1996b. Cotton Production Manual. DANR Publication 3352. $417 \mathrm{p}$.

Division of Agriculture and Natural Resources (DANR), UC. 1991. CALEX/Cotton User's Guide Version 4.0, UC IPM Publication 8. Davis. $186 \mathrm{p}$.

Division of Agriculture and Natural Resources (DANR), UC. 1998. UC IPM Pest Management Guidelines. In: UC IPM Pest Management Guidelines, UC DANR Publication 3339. 1,600 p.

Gliessman SR, Werner MR, Swezey SL, et al. 1996. Conversion to organic strawberry management changes ecological processes.

Cal Ag 50(1): 24-31.

Grafton-Cardwell EE, Godfrey LD,

Brindley WA, Goodell PB. 1997. Status of lygus bug and cotton aphid resistance in the San Joaquin Valley. Proceedings, Beltwide Cotton Conferences 2:1072-4.

Hsieh Y-L, Honik E, Hartzell MM. 1995. A developmental study of single fiber strength:

Greenhouse grown SJ-2 Acala cotton. Textile Research J 65(2):101-12.

Kerby TA, Keely M, Johnson S. 1987. Growth and development of Acala cotton. UC Experiment Station Bulletin 1921. $16 \mathrm{p}$. Sevacharian V, Stern VM. 1974. Host plant preference of lygus bugs in alfalfa interplanted cotton fields. Envir Ent 3:761-6.

Swezey SL, Rider J, Werner M, et al. 1994. Granny Smith conversions to organic show early success. Cal Ag 48(6):36-44. 